\title{
Dietary Supplementation with Probiotic Strain Improves Immune-Health in Aged Mice
}

\author{
Verónica Molina*, Marta Médici*, Julio Villena, Graciela Font, María Pía Taranto\# \\ CERELA-Centro de Referencia para Lactobacilos (CONICET), Chacabuco No. 145 (T4000ILC) San Miguel de \\ Tucumán, Tucumán, Argentina \\ Email: ptaranto@cerela.org.ar
}

Received 19 April 2016; accepted 2 August 2016; published 5 August 2016

Copyright (c) 2016 by authors and Scientific Research Publishing Inc.

This work is licensed under the Creative Commons Attribution International License (CC BY).

http://creativecommons.org/licenses/by/4.0/

(c) () Open Access

\begin{abstract}
Ageing is associated with several anatomical and physiological changes of the organism, and the increase in global elderly population promotes the research to develop strategies to improve their quality of life. In this work, we characterized the immunological alterations naturally produced during aging in a mice model, and evaluated the effect of probiotic Lactobacillus (L.) rhamnosus CRL1505 administration on those immunological parameters. We demonstrated that L. rhamosus CRL1505 was able to improve peritoneal macrophages phagocytic activity, and the number of intestinal $\mathrm{IgA}^{+}$cells in aged mice, reaching values of those parameters similar to young adult mice. The results of this work indicate that is plausible that the immunobiotic CRL1505 strain may find applications as a beneficial immunomodulator in aging to reinforce the intestinal and systemic immunity. The immune modulation in aging induced by L. rhamnosus CRL1505 could lead to the development of new strategies for functional foods specifically tailored for the elderly.
\end{abstract}

\section{Keywords}

Aging, Inmunobiotic, Immunosenescence, L. rhamnosus CRL1505

\section{Introduction}

Aging is a manifold of universal biological processes that profoundly alter anatomy and physiology of all organisms. Substantial increases in the relative and absolute number of older persons in our societies have posed a challenge for medicine, as successful aging is multidimensional for maintaining high physical and cognitive

\footnotetext{
${ }^{*}$ These authors contribute equally to the paper.

"Corresponding author.
}

How to cite this paper: Molina, V., Médici, M., Villena, J., Font, G. and Taranto, M.P. (2016) Dietary Supplementation with Probiotic Strain Improves Immune-Health in Aged Mice. Open Journal of Immunology, 6, 73-78. 
function for sustained engagement in social and productive activities. A key factor is the maintenance of normal immune functions to provide immediate response to pathogens and to integrate and influence the adaptive immune response [1] which is diminished in aged population. The mechanisms underlying these changes are now beginning to be characterized and include alterations in the activity of a variety of immune cell receptors and their downstream signalling pathways as well as changes to the numbers of immune cells [2].

Functional probiotic foods have been shown to have several beneficial effects in elderly subjects including the reduction of constipation, modulation of serum cholesterol levels, improvement of the balance of intestinal flora, and immunomodulatory activities [3]. Recent advances in understanding the effect of probiotics on the aging immune system have begun to unfold their potent anti-immunosenescence attributes, e.g., modulation of cytokines production, improvement of NK cells, neutrophils and macrophages activities as well as enhancement of mucosal and systemic antibodies production [4] [5].

We have previously reported that Lactobacillus (L.) rhamnosus CRL1505, strain isolated from goat milk, has probiotic properties. Studies in mice models show that administration of CRL1505 strain enhances the resistance against intestinal and respiratory pathogens in infant and young adult mice, improving both systemic and mucosal immune responses [6] [7]. These effects were related to the capacity of L. rhamnosus CRL1505 to beneficially regulate the balance between inflammatory and regulatory cytokines, improve phagocytes activity, and enhance systemic and mucosal humoral immune responses [6]. The immunobiotic strain L. rhamnosus CRL1505 also proved to beneficially modulate both gut and respiratory illnesses in children under 5 years old, which was related to an improvement of mucosal immunity [8]. The effect of L. rhamnosus CRL1505 administration to aged host, however, has not been studied before.

The effect of probiotics may be different according to the physiological state of the subjects. This suggests that for aging studies, it is imperative to analyse probiotic effects in appropriate experimental models of aged subjects rather than extrapolating results from studies on young adult population. From these considerations, this study is undertaken to find out whether the immunobiotic L. rhamnosus CRL1505 exerts beneficial effects in aged hosts.

\section{Materials and Methods}

\subsection{Microorganism and Growth Conditions}

L. rhamnosus CRL1505 (culture collection CERELA, Tucumán, Argentina) was grown independently in a milk-based culture medium added with sugar and salts (under patent) for bulk biomass production. Batch fermentations were carried out in a 2.5L-bioreactor (Infors HT, Switzerland) at $37^{\circ} \mathrm{C}$ and pH 5.5 for $22 \mathrm{~h}$. Bacteria were harvested and washed twice (sterile saline solution) by centrifugation $\left(7000 \times \mathrm{g}, 10 \mathrm{~min}, 4^{\circ} \mathrm{C}\right)$ and suspended in $40 \%(\mathrm{w} / \mathrm{v})$ reconstituted skim milk (RSM) containing 5\% (w/v) food grade monosodium glutamate. The cell suspension was spray-dried (Buchi B-290, Switzerland) and the inmunobiotic powder obtained was stored at $-20^{\circ} \mathrm{C}$ before using.

\subsection{Animals and Feeding Procedure}

Female BALB/c aged mice (64-weeks old) were obtained from the closed colony of the breeding unit kept at CERELA Institute (San Miguel de Tucumán, Argentina) housed in plastic cages and maintained at $20 \pm 2^{\circ} \mathrm{C}$ with a 12-h light/dark cycle. Animal studies and protocols were approved by the CERELA Ethical Committee of Animal Care with the identification CRL-BIOT-LTD-2008/1A.

Mice were randomly allocated to four main experimental groups as follows: EBc group (Elderly Basal control group) elderly mice that received water ad libitum; EM group (Elderly Milk group) elderly mice that received RSM ad libitum; E-1505 group (Elderly + 1505 group) elderly mice that received L. rhamnosus CRL1505; YB group (Young Basal) young mice (mice 6-weeks old) that received water ad libitum. This last group was used as reference but not as control group. All groups were allowed free access to the conventional balanced diet. $L$. rhamnosus CRL1505 was administered to E-1505 group at $10^{8}$ cells/mouse/day in RSM during 7 consecutive days.

\subsection{Peritoneal Macrophages Phagocytic Activity}

Peritoneal macrophages were obtained as described previously [9]. Cell concentration was adjusted at $1 \times 10^{6}$ 
cells $/ \mathrm{ml}$. Phagocytosis assay was performed using Saccharomyces boulardii suspension at a concentration of $10^{7}$ cells $/ \mathrm{ml}$. Opsonized yeast in mouse autologous serum $(10 \%)$ were added to $0.2 \mathrm{ml}$ of macrophage suspension. The mixture was incubated at $37^{\circ} \mathrm{C}$ for $30 \mathrm{~min}$. The percentage of phagocytosis was expressed as the percentage of phagocyting macrophages in 200 cells counted with an optical microscope.

\subsection{IgA+ Cell in the Small Intestine}

The small intestines were removed and washed with saline solution $(\mathrm{NaCl} 0.15 \mathrm{M})$. Tissues were prepared according to Vinderola et al. [10]. Serial paraffin sections $(4 \mu \mathrm{m})$ were made and used for immunofluorescence assays to determine IgA positive cells in the lamina propria of the intestine. IgA detection was performed by using (a-chain specific) anti-mouse IgA FITC conjugated (Sigma-Aldrich, USA). Histological samples were incubated with the antibody dilution (1/100) in PBS (Phosphate Buffer Sodium 0.1 M, pH 7) solution for 30 min at $37^{\circ} \mathrm{C}$. Samples were then washed three times with PBS solution and examined by using a fluorescent light microscope. Results were expressed as the number of IgA-producing cells (positive: fluorescent cell) per 10 fields (magnification 100×). Results were the mean of three histological slices for each animal.

\subsection{Statistical Analysis}

Experiments were performed in triplicate and results were expressed as means $\pm \mathrm{SD}$. Statistical analysis was conducted using MINITAB software (version 15 for Windows). 2-factor ANOVA was used to test the effects of experimental group, time, and their interaction. Tukey's post hoc test was used to test for differences between the mean values. Significance was set at $\mathrm{P}<0.05$.

\section{Results and Discussion}

Immune functions are known to deteriorate with age in several species, a process known as immunosenescence. In humans, the elderly are at a higher risk for infections and the immune response to vaccination is diminished [1]. Age-associated immune deregulation occurs in both the mucosal and the systemic immune compartments, and affects innate and adaptive immune responses. In this work, we showed that peritoneal macrophages phagocytic activity and $\operatorname{Ig} \mathrm{A}^{+}$cells in the small intestine of aged mice were significantly reduced when compared to young mice.

As observed in Figure 1, macrophages phagocytic activity was significantly reduced in elderly (EBc

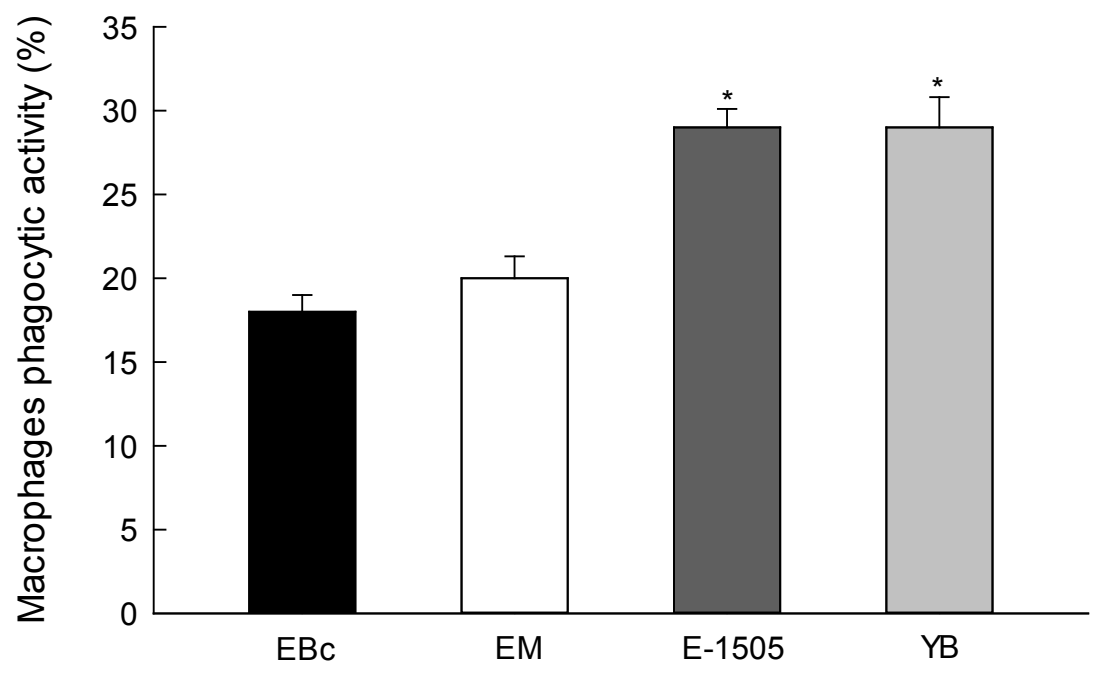

Figure 1. Effect of aging and immunobiotic Lactobacillus rhamnosus CRL1505 administration on phagocytic activity. EBc group (Elderly Basal control) $(\mathrm{n}=6)$; EM group (Elderly Milk) $(\mathrm{n}=6)$; E-1505 group (Elderly + L. rhamnosus 1505$)(\mathrm{n}=6)$; YB group (Young Basal) $(n=6)$. The results represent data from three independent experiments. Results are expressed as mean \pm SD. ${ }^{*}$ Significant differences $(\mathrm{P}<0.05)$ with EBc group. 
group) $(18 \pm 1.0 \%)$ compared to young mice (YBc group) $(29 \pm 1.8 \%)$. Administration of milk to EM group did not induce any significant change in these parameters $(20 \pm 1.3 \%)$ while an increase in the aged group fed the immunobiotic CRL1505 strain (E-1505 group) $(29 \pm 1.1 \%)$ was observed, reaching values similar to the young mice.

The monocytes/macrophage system is an essential cellular part of the innate immune response. These cells play important functions to control microorganisms and are the link to the adaptive immune system via their role in antigen presentation. There is clear evidence that phagocytosis and killing capacities of macrophages are also reduced with age, due to lower production of reactive oxygen species (ROS) such as $\mathrm{NO}_{2}$ and $\mathrm{H}_{2} \mathrm{O}_{2}$ [2]. In addition, age-associated changes in human and mice macrophages include altered expression and function of pattern recognition receptors, diminished expression of major histocompatibility complex (MHC) class II molecules, reduced response to IL-12 and IFN- $\gamma$, and altered production of cytokines [2]. Several studies have demonstrated that probiotics are able to reduce age-associated changes on phagocytic cells. It was reported that administration of the probiotic strains L. acidophilus LaVK2 or B. bifidum BbVK3 ameliorate age induced deficits in phagocytic activity of peritoneal macrophages with corresponding increase in production of reactive oxygen species [11]. It was also reported that oral administration of L. lactis subsp. cremoris H61, a lactococcal strain with known immunomodulatory activity, to senescence-accelerated SAMP6 mice was associated with an improved production of IL-12 and IFN- $\gamma$ in spleen cells indicating that the probiotic strain enhanced the Th1-type immune [12]. Similarly, Sharma et al. recently showed that consumption of L. rhamnosus MTCC 5897 fermented milk in aging mice significantly improved Th1 response [13]. The study found that probiotic treatment enhanced phagocytic and microbicidal activities of neutrophils. Besides, it was reported that the oral administration of $B i$ fidobacterium strains isolated from healthy centenarians was able to enhanced immune function in mice by increasing the phagocytic activity of peritoneal macrophages [14]. Our results are in line with those previous studies and indicate that L. rhamnosus CRL1505 could help to maintain macrophages performance during aging since their activity in aged mice that received the probiotic was similar to those found in young adults. Previous studies in young mice showed that L. rhamnosus CRL1505 increases intestinal and blood IFN- $\gamma$ levels. Considering that IFN- $\gamma$ is the principal macrophage-activating cytokine and serves critical functions in innate immunity, improved production of this cytokine mediates the stimulation of peritoneal macrophages by the CRL1505 strain [9]. Thus, we consider that this mechanism would be similar in aged mice after consumption of L. rhamnosus CRL1505.

Figure 2 shows the number of $\mathrm{IgA}^{+}$cells in the small intestine of the different experimental groups. This parameter was reduced in elderly, EBc group ( $56 \pm 2.3$ cells/10 fields), compared to young mice (YBc group)

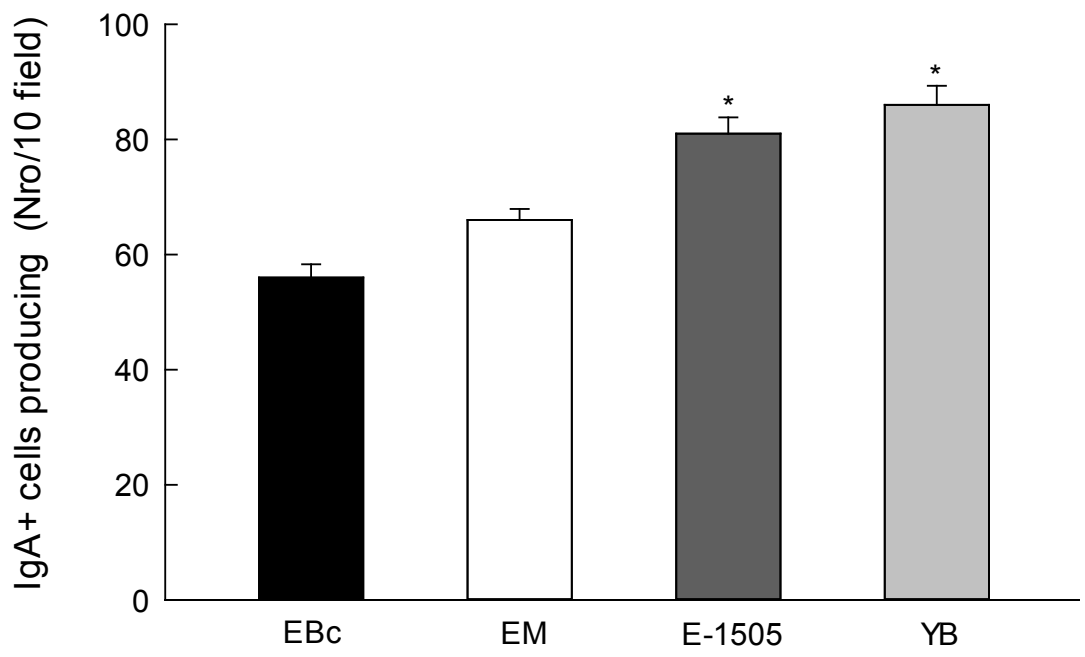

Figure 2. Effect of aging and immunobiotic Lactobacillus rhamnosus CRL1505 administration on intestinal IgA producing cells. EBc group (Elderly Basal control) $(\mathrm{n}=6)$; EM group (Elderly Milk) $(\mathrm{n}=6)$; E-1505 group (Elderly + L. rhamnosus 1505) $(n=6)$; YB group (Young Basal) $(n=6)$. The results represent data from three independent experiments. Results are expressed as mean \pm SD. ${ }^{*}$ Significant differences $(\mathrm{P}<0.05)$ with $\mathrm{EBc}$ group. 
$\left(86 \pm 3.0\right.$ cells/10 fields). Administration of milk to EM group did not induce any significant change in IgA ${ }^{+}$ cells $(66 \pm 1.9$ cells/10 fields) while an increase in the aged group fed the immunobiotic CRL1505 strain, E-1505 ( $81 \pm 2.8$ cells/10 fields) was observed, with values similar to the young mice.

The intestinal tract in the elderly is particularly susceptible to infectious diseases suggesting that a poor mucosal immunity is a major factor leading to higher mortality from infections in aging [1]. In fact, studies showed that the mucosal immune system is affected by immunosenescence earlier than the systemic immune system and that this effect is translated into an age-associated impairment of mucosal secretory IgA antibody responses [15] [16]. It was also reported that probiotics are able to improve IgA levels affected by aging. Kaburagi et al. showed that total intestinal IgA, which was measured from fecal extract, was augmented in aged mice after the treatment with L. johnsonii La1 [17]. Moreover, the work also reported that probiotic administration was capable of increasing the production of antigen specific IgA induced by immunization of aged mice. Similarly, we demonstrated here that administration of the immunobiotic strain CRL1505 to aged mice improved IgA ${ }^{+}$cells in the intestinal mucosa. This is in line with our previous studies that reported an increase in the number of $\operatorname{IgA}{ }^{+}$ cells in the lamina propria of the small intestine of young mice after oral treatment with this immunobiotic strain [6]. The increase in the intestinal IgA levels is important because it prevents the colonization of this mucosal tissue by pathogens and their subsequent spreading into the systemic circulation. Additionally, IgA antibodies can bind antigens and minimize their entry with a consequent reduction in inflammatory reactions, which prevents potentially harmful effects on the tissue. Thus, the improvement of the levels of IgA ${ }^{+}$cells induced by the CRL1505 strain in aged mice could increase their resistance to the challenge with intestinal pathogens.

There is significant evidence showing that several physiological functions are altered by advanced aging, and that some probiotic strains are able to reduce some of those alterations. The results of this work indicate that is plausible that the immunobiotic strain L. rhamnosus CRL1505 may find applications as a beneficial immuneomodulator in aging to reinforce the intestinal and systemic immunity. The immune modulation in aging induced by L. rhamnosus CRL1505 could lead to the development of new strategies for functional foods specifically tailored for the elderly.

\section{Acknowledgements}

This study was carried out with the financial support from CONICET (PIP0406/12) and MinCyT (PICT2011 $\left.\mathrm{N}^{\circ} 0175\right)$ from Argentina.

\section{References}

[1] Sato, S., Kiyono, H. and Fujihashi, K. (2015) Mucosal Immunosenescence in the Gastrointestinal Tract. A Mini-Review Gerontology, 61, 336-342.

[2] Solana, R., Tarazona, R., Gayoso, I., Lesur, O., Dupuis, G. and Fulop, T. (2012) Innate Immunosenescence: Effect of Aging on Cells and Receptors of the Innate Immune System in Humans. Seminars in Immunology, 24, 331-341. http://dx.doi.org/10.1016/j.smim.2012.04.008

[3] Hamilton-Miller, J.M.T. (2004) Probiotics and Prebiotics in the Elderly. Postgraduate Medical Journal, 80, $447-451$. http://dx.doi.org/10.1136/pgmj.2003.015339

[4] Malaguarnera, G., Leggio, F., Vacante, M., Motta, M., Giordano, M., Bondi, A., Basile, F., Mastrojeni, S., Mistretta, A., et al. (2012). Probiotics in the Gastrointestinal Diseases of the Elderly. The Journal of Nutrition, Health \& Aging, 16, 402-410. http://dx.doi.org/10.1007/s12603-011-0357-1

[5] Biagi, E., Candela, M., Fairweather-Tait, S. and Brigidi, P. (2012) Ageing of the Human Metaorganism: The Microbial Counterpart. $A G E, \mathbf{3 4}, 247-267$. http://dx.doi.org/10.1007/s11357-011-9217-5

[6] Salva, S., Villena, J. and Alvarez, S. (2010) Differential Immunomodulatory Activity of Lactobacillus rhamnosus Strains Isolated from Goat Milk: Impact on Intestinal and Respiratory Infections. International Journal of Food Microbiology, 141, 82-89. http://dx.doi.org/10.1016/j.ijfoodmicro.2010.03.013

[7] Villena, J., Chiba, E., Tomosada, Y., Salva, S., Marranzino, G., Kitazawa, H. and Alvarez, S. (2012) Orally Administered Lactobacillus rhamnosus Modulates the Respiratory Immune Response Triggered by the Viral Pathogen-Associated Molecular Pattern Poly(I:C). BMC Immunology, 13, 53-66.

[8] Villena, J., Salva, S., Núñez, M., Corzo, J., Tolaba, R., Faedda, J., et al. (2012) Probiotics for Evzeryone! The Novel Immunobiotic Lactobacillus rhamnosus CRL1505 and the Beginning of Social Probiotic Programs in Argentina. International Journal of Biotechnology for Wellness Industries International, 1, 189-198. 
[9] Marranzino, G., Villena, J., Salva, S. and Alvarez, S. (2012) Stimulation of Macrophages by Immunobiotic Lactobacillus strains: Influence beyond the Intestinal Tract. Microbiology and Immunology, 56, 771-781. http://dx.doi.org/10.1111/j.1348-0421.2012.00495.x

[10] Vinderola, C.G., Medici, M. and Perdigón, G. (2004) Relationship between Interaction Sites in the Gut, Hydrophobicity, Mucosal Immunomodulating Capacities and Cell Wall Protein Profiles in Indigenous and Exogenous Bacteria. Journal of Applied Microbiology, 96, 230-243. http://dx.doi.org/10.1046/j.1365-2672.2004.02158.x

[11] Kaushal, D. and Kansal, V. (2014) Dahi Containing Lactobacillus acidophilus and Bifidobacterium bifidum Improves Phagocytic Potential of Macrophages in Aged Mice. Journal of Food Science and Technology, 51, 1147-1153. http://dx.doi.org/10.1007/s13197-012-0637-8

[12] Kimoto-Nira, H., Susuki, Ch., Kobayashi, M., Sasaki, K., Kurisaki, J. and Mizumachi, K. (2007) Anti-Ageing Effect of a Lactococcal Strain: Analysis Using Senescence-Accelerated Mice. British Journal of Nutrition, 98, 1178-1186. http://dx.doi.org/10.1017/S0007114507787469

[13] Sharma, R., Kapila, R., Dass, G. and Kapila, S. (2014) Improvement in Th1/Th2 Immune Homeostasis, Antioxidative Status and Resistance to Pathogenic E. coli on Consumption of Probiotic Lactobacillus rhamnosus Fermented Milk in Aging Mice. $A G E$, 36, 9686-9703. http://dx.doi.org/10.1007/s11357-014-9686-4

[14] Yang, H.Y., Liu, S.L., Ibrahim, S.A., Zhao, L., Jiang, J.L., Sun, W.F. and Ren, F.Z. (2009) Oral Administration of Live Bifidobacterium Substrains Isolated from Healthy Centenarians Enhanced Immune Function in BALB/c Mice. Nutrition Research, 29, 281-289. http://dx.doi.org/10.1016/j.nutres.2009.03.010

[15] Koga, T., McGhee, J.R., Kato, H., Kato, R., Kiyono, H. and Fujihashi, K. (2000) Evidence for Early Aging in the Mucosal Immune System. Journal of Immunology, 165, 5352-5359. http://dx.doi.org/10.4049/jimmunol.165.9.5352

[16] Hagiwara, Y., McGhee, J.R., Fujihashi, K., Kobayashi, R., Yoshino, N., Kataoka, K., et al. (2003) Protective Mucosal Immunity in Aging Is Associated with Functional CD4+ T Cells in Nasopharyngeal-Associated Lymphoreticular Tissue. Journal of Immunology, 170, 1754-1762. http://dx.doi.org/10.4049/jimmunol.170.4.1754

[17] Kaburagi, T., Yamano, T., Fukushima, Y., Yoshino, H., Mito, N. and Sato, K. (2007) Effect of Lactobacillus johnsonii La1 on Immune Function and Serum Albumin in Aged and Malnourished Aged Mice. Nutrition, 23, 342-350. http://dx.doi.org/10.1016/j.nut.2007.02.001

\section{Submit or recommend next manuscript to SCIRP and we will provide best service for you:}

Accepting pre-submission inquiries through Email, Facebook, LinkedIn, Twitter, etc.

A wide selection of journals (inclusive of 9 subjects, more than 200 journals)

Providing 24-hour high-quality service

User-friendly online submission system

Fair and swift peer-review system

Efficient typesetting and proofreading procedure

Display of the result of downloads and visits, as well as the number of cited articles

Maximum dissemination of your research work

Submit your manuscript at: http://papersubmission.scirp.org/ 